\title{
ScIDoC
}

\author{
International Journal of Dentistry and Oral Science (IJDOS) \\ ISSN: 2377-8075
}

\section{Relationship Between Plaque Score and Cariogram Risk Prediction Parameters among Patients Visiting A Dental Institution: Retrospective Study}

Research Article

Harini Kumaran ${ }^{1}$, SS Raj ${ }^{*}$, Niveditha.M.S

${ }^{1}$ Saveetha Dental College and Hospitals, Saveetha Institute of Medical and Technical Sciences, Saveetha University, Chennai, India.

${ }^{2}$ Reader, Department of Public Health Dentistry, Saveetha Dental College and Hospitals, Saveetha Institute of Medical and Technical Sciences, Saveetha University, Chennai, 600077, India.

${ }^{3}$ Professor, Dept of Conservative Dentistry \& Endodontics, Saveetha Dental College and Hospitals, Saveetha Institute of Medical and Technical Sciences, Saveetha University, Chennai, 600077, India.

\section{Abstract}

Etiology of dental caries is multifactorial.Currently, caries risk assessment models contain a combination of factors such as diet, fluoride exposure, a susceptible host, microflora that interact with the variety of social, cultural and behavioural factors. The aim of the study was to assess the relationship between plaque score and cariogram risk prediction parameters among patients visiting a dental institution in Chennai. This was a retrospective institutional study. Samples were collected from June 2019 to March 2020 from patient records who visited a private dental hospital. Sample size was about 221. Details on plaque score and cariogram factors were collected from patient records and tabulated in microsoft excel tabulation and analyzed using SPSS. P $<0.05$ considered significant. Mean age of males and females were found to be 33.3479 and 36.7212 years and the difference is statistically significant $(\mathrm{p}<0.05)$. The mean of plaque index score in male and female was found to be 1.3346 and 1.4497 , mean percentage of avoiding new cavities was found to be 45.3846 in male and 42.6250 in female, mean of circumstances was found to be 11.5812 in males and 11.2692 in females, mean of bacteria was found to be 16.2564 in males and 18.0865 in females, mean of susceptibility was found to be 16.9658 in males and 19.2885 in females, mean of diet was found to be 9.1026 in males, 8.8654 in females. There was no association between gender and plaque index score, cariogram categories $(\mathrm{p}>0.05)$ and no correlation between plaque index score and cariogram risk factors. Within the limitations of the present study, we can conclude that there is no correlation between plaque score and cariogram risk factors.

Keywords: Bacteria; Caries; Cariogram; Diet; Plaque Score.

\section{Introduction}

Dental caries is one of the most common important global oral health problems in the world today. It hinders the maintenance of oral health in all age groups $[1,2]$. Dental caries are multifactorial disease. There are many risk factors which contribute to their initiation and progression. They can be categorised as biological, environmental or social behavioral $[3,4]$. There is no single test that takes into consideration all the factors which can accurately predict an individual's susceptibility to caries [5]. Dental plaque is the community of microorganisms found on a tooth surface as a biofilm $[6,7]$. If this biofilm is not removed regularly, it undergoes maturation and leads to dental caries, gingivitis \& periodontitis.
In addition, subgingival plaque with periodontitis has also been associated with systemic diseases such as cardiovascular disease, diabetes, respiratory diseases and adverse pregnancy complications [8]. Plaque index scoring was given by Silness and Loe. Accurate prediction of caries risk help in directly targeted preventive actions to those at high caries risk before cavities could develop. Currently, The Cariogram is a caries risk assessment tool that uses an algorithm to assess caries risk. It analyses the biological factors such as past caries experience, related diseases, diet contents $\&$ frequency, plaque amount, Mutans streptococci count, fluoride programme, saliva secretion \& buffer capacity. It also expresses the magnitude at which multiple etiological factors of caries affect that particular patient risk. There are five sectors in the cariogram.

\footnotetext{
*Corresponding Author

SS Raj,

Reader, Department of Public Health Dentistry, Saveetha Dental College and Hospitals, Saveetha Institute of Medical and Technical Sciences, Saveetha University, Chennai, 600077, India.

Tel: 7010395428

E-mail: samuelrajs.sdc@saveetha.com

Received: October 07,2020

Accepted: November 22, 2020

Published: November 25, 2020

Citation: Harini Kumaran, SS Raj, Niveditha.M.S. Relationship Between Plaque Score and Cariogram Risk Prediction Parameters among Patients Visiting A Dental Institution: Retrospective Study. Int J Dentistry Oral Sci. 2020;7(11):1049-1053. doi: http://dx.doi.org/10.19070/2377-8075-20000207

Copyright: SS Raj ${ }^{\circ} 2020$. This is an open-access article distributed under the terms of the Creative Commons Attribution License, which permits unrestricted use, distribution and reproduction in any medium, provided the original author and source are credited.
} 
Dark blue colour indicates diet (diet contents and diet frequency), red sector which indicates bacteria- amount of plaque $\&$ mutans streptococci, light blue sector indicates susceptibility (fluoride programme, saliva secretion \& buffer capacity), yellow sector indicates circumstances (past caries experience \& related diseases), green sector denotes actual chance to avoid caries, it is the sector what is left after the other factors take their segment [9]. Previously our college had conducted many clinical trials [10-13], in vitro studies [14, 15], in vivo studies [16] and other studies [17-24] in the last five years. Now we are focussed on retrospective studies. Hence a retrospective study was planned to assess the prevalence of plaque score and cariogram risk among patients visiting dental institution.

\section{Materials and Methods}

The present study was a retrospective study done in a university setting. This study was conducted at Saveetha Dental college and hospital, Chennai and ethical approval of the study was obtained from the Institutional ethics committee (Saveetha Research Board). Ethical approval number of this study is SDC/SIHEC/2020/DIASDATA/0619-0320. 221 patients records from Saveetha Dental College were assessed for plaque index scores and cariogram risk categories. Patient records with both plaque index score and cariogram risk assessment were included in this study. Patient records without plaque index scores and incomplete cariogram risk assessment were excluded in this study. Cross verification was done with photographs. Sampling Bias was minimised by convenience sampling. Sample data was cross verified by another examiner to avoid any missing data. Data was entered in a methodological manner using microsoft excel. Data was imported into SPSS, version 20 for data analysis. Descriptive statistical test was done using SPSS software. Independent variables were gender. Dependent variables were plaque score and cariogram risk factors. Descriptive analysis was done and the mean of plaque score and various cariogram categories was assessed using an independent $\mathrm{T}$ test. $\mathrm{P}<0.05$ was considered Significant.

\section{Results and Discussion}

Among 221 sample patients, plaque score index scoring and their cariogram details were collected. Among them, 117 were male and 104 were female. The mean age of male and female was found to be 33.2479 and 36.7212 and the difference is statistically significant $(\mathrm{p}<0.05)$. The mean of plaque index score in male and female was found to be 1.3346 and 1.4497 , mean of avoiding new cavities was found to be 45.3846 in male and 42.6250 in female, mean of circumstances was found to be 11.5812 in males and 11.2692 in females, mean of bacteria was found to be 16.2564 in males and 18.0865 in females, mean of susceptibility was found to be 16.9658 in males and 19.2885 in females, mean of diet was found to be 9.1026 in males, 8.8654 in females. There was no statistical significance between gender and plaque index score and cariogram categories $(\mathrm{p}>0.05)$. (Table 1). Sreenivasan et al in his study reported no statistical differences in whole mouth plaque scores between genders [25]. Al Haddad et al reported a significantly higher mean of plaque index in males than females in 12 year olds, not in 5 year olds [26].

In this study, there was no correlation between cariogram categories and plaque index (Figure 1,2,3,4,5). Ekstrand et al reported no statistical significance was observed between plaque scores on sound and carious surfaces. He also added that no significant difference was observed between plaque scores in caries with caries progression as compared with no caries progression ( $p>0.05)$ [27]. Morinushi et al reported that poor oral hygiene is directly associated with plaque score and contributes to high prevalence of dental caries [28]. Anu Garg et al reported a statistically significant difference was found between plaque index score and actual chance to avoid caries [29]. Clelick et al reported the participants with good oral hygiene developed fewer new carious lesions than the ones with poor or very poor oral hygiene $(\mathrm{P}<0.05)[30,31]$. Similar results have been seen in studies by Heabbal et al $[30,31]$. Basha et al., reported significant difference in caries prevalence in relation to age, use of fluoridated toothpaste, plaque score, enamel defects and dental visits [32]. Lingstorm in his study concluded

Table 1. Table shows the mean age, plaque index score and cariogram categories in males and females. There was a significant difference in age between male and female $(\mathrm{p}<0.05)$. However, there was no association between gender and plaque index score, cariogram categories $(\mathrm{p}>0.05)$.

\begin{tabular}{|c|c|c|c|c|c|}
\hline & Gender & $\mathbf{N}$ & Mean & Std. Deviation & $P$ value \\
\hline \multirow{2}{*}{ Age } & Male & 117 & 33.248 & 10.569 & \multirow{2}{*}{0.018} \\
\hline & Female & 104 & 36.721 & 11.036 & \\
\hline \multirow{2}{*}{ Plaque Index score } & Male & 117 & 1.335 & 0.918 & \multirow{2}{*}{0.484} \\
\hline & Female & 104 & 1.450 & 1.483 & \\
\hline \multirow{2}{*}{ Avoid New cavities } & Male & 117 & 45.385 & 23.271 & \multirow{2}{*}{0.411} \\
\hline & Female & 104 & 42.625 & 26.142 & \\
\hline \multirow{2}{*}{ Circumstances } & Male & 117 & 11.581 & 8.494 & \multirow{2}{*}{0.777} \\
\hline & Female & 104 & 11.269 & 7.778 & \\
\hline \multirow{2}{*}{ Bacteria } & Male & 117 & 16.256 & 8.045 & \multirow{2}{*}{0.103} \\
\hline & Female & 104 & 18.087 & 8.565 & \\
\hline \multirow{2}{*}{ Susceptibility } & Male & 117 & 16.966 & 9.814 & \multirow{2}{*}{0.118} \\
\hline & Female & 104 & 19.289 & 12.192 & \\
\hline \multirow{2}{*}{ Diet } & Male & 117 & 9.103 & 5.806 & \multirow{2}{*}{0.768} \\
\hline & Female & 104 & 8.865 & 6.149 & \\
\hline
\end{tabular}


Figure 1. Depicts correlation between plaque index score with the percentage of avoiding new cavities. $X$ axis represents plaque index score and $\mathrm{Y}$ axis represents the mean percentage of avoiding new cavities. From the present graph it can be inferred that there is no correlation found between the plaque index score and avoiding new cavities in our sample when assessed using pearson correlation test $(\mathrm{r}=0.067, \mathrm{p}$ value $=0.323)$.

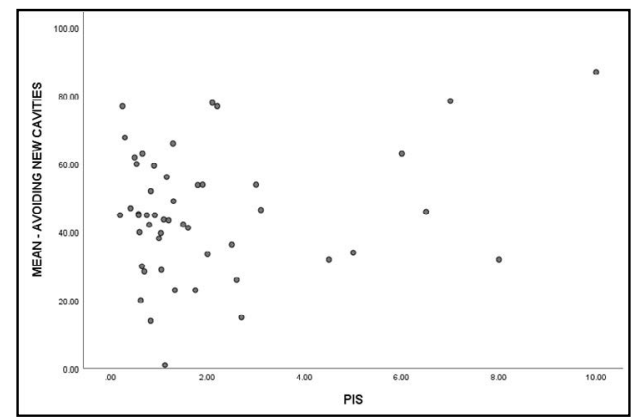

Figure 2. Depicts correlation between plaque index score with the percentage of circumstances in cariogram. $\mathrm{X}$ axis represents plaque index score, $Y$ axis represents mean percentage of circumstances. From the present graph it can be inferred that there is no correlation found between the plaque index score and circumstances in our sample when assessed using pearson correlation test $(\mathrm{r}=0.041, \mathrm{p}$ value $=0.546)$.

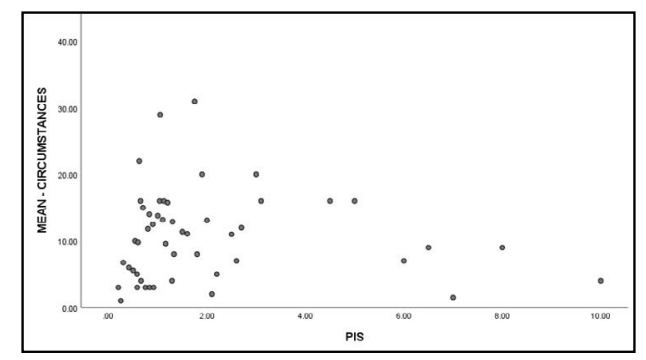

Figure 3. Depicts correlation between plaque index score with the mean percentage of bacteria. $\mathrm{X}$ axis represents plaque index score, $\mathrm{Y}$ axis represents mean percentage of bacteria. From the present graph it can be inferred that there is no correlation found between the plaque index score and bacteria in our sample when assessed using pearson correlation test $(r=0.006, p$ value $=0.931)$.

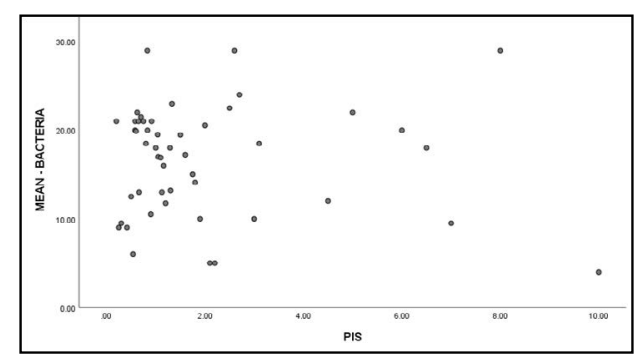

Figure 4. Depicts correlation between plaque index score with the mean percentage of susceptibility. $\mathrm{X}$ axis represents plaque index score, $Y$ axis represents mean percentage of susceptibility. From the present graph it can be inferred that there is no correlation found between the plaque index score and susceptibility in our sample when assessed using pearson correlation test $(\mathrm{r}=: 0.077, \mathrm{p}$ value $=\mathbf{0 . 2 5 6})$.

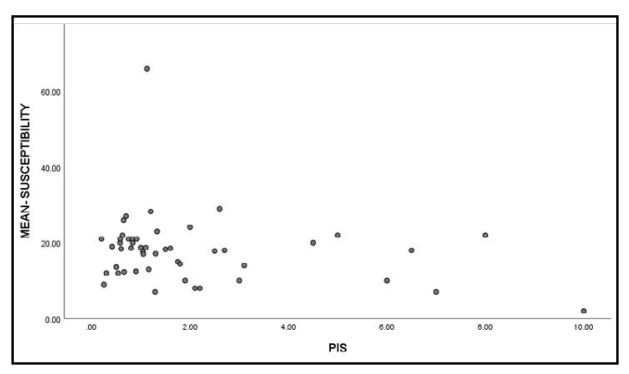

that caries status is characterized by plaque levels of highly tolerant, acidogenic bacteria, PH lowering potential plaque [33]. Sudhir et al reported that the amount of plaque was found to be significantly associated with caries activity in the study population [34].

The presence of dental plaque is a prerequisite for carie development and if this biofilm is not present caries will not develop, regardless of any other risk factors [35]. Dental plaque ferments carbohydrates which leads to production of organic acids. These organic acids lead to demineralisation of the tooth surface, and consequently to dental caries. Saliva is also unable to penetrate plaque and thus cannot neutralize the acid produced by bacteria and remineralize the tooth surface [36].

Limitations of this study include small sample size which does not provide results of the entire population. Since it was a ret- 
Figure 5. Depicts association of Plaque index score with mean of diet. $\mathrm{X}$ axis represents plaque index score, $\mathrm{Y}$ axis represents the mean percentage of diet from cariogram. From the present graph it can be inferred that there is no correlation found between the plaque index score and diet in our sample when assessed using pearson correlation test $(\mathrm{r}=: 0.052, \mathrm{p}$ value $=0.444)$.

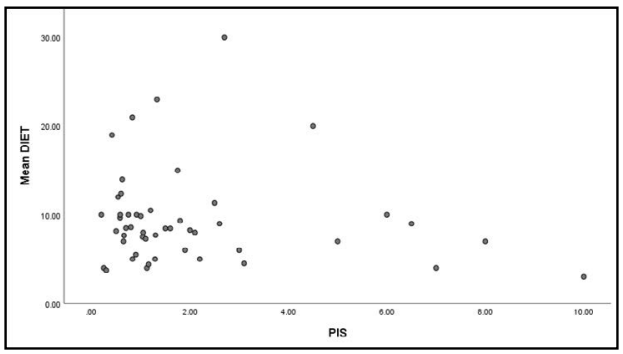

rospective study, possible manual errors can occur during data entry by residents during patients examination, subjective bias was another limitation of this study.

\section{Conclusion}

Within the limitations of the present study, we can conclude that there is no correlation between plaque score and cariogram risk factors among the subjects in our sample. However, generalization of this result should be done carefully as the clinician has to use cariogram as an adjunct and not as a substitute for clinical evaluation of an individual's oral health status. Future studies with larger populations are required to confirm the relationship between plaque score and cariogram risk factors in the south Indian population.

\section{Acknowledgement}

The authors are thankful to Saveetha Dental College for providing permission to access the database and for giving a platform to express our knowledge.

\section{References}

[1]. Khushbu Y, Satyam P. Dental caries: A review. Asian Journal of Biomedical and Pharmaceutical Sciences. 2016;6(53):1-7.

[2]. Thean $\mathrm{H}$, Wong ML, Koh $\mathrm{H}$. The dental awareness of nursing home staff in Singapore - a pilot study. Gerodontology. 2007 Mar;24(1):58-63.Pubmed PMID: 17302933.

[3]. Elamin A, Garemo M, Gardner A. Dental caries and their association with socioeconomic characteristics, oral hygiene practices and eating habits among preschool children in Abu Dhabi, United Arab Emirates - the NOPLAS project. BMC Oral Health. 2018 Jun 8;18(1):104.Pubmed PMID: 29884158.

[4]. Selwitz RH, Ismail AI, Pitts NB. Dental caries. The Lancet. 2007 Jan 6;369(9555):51-9.

[5]. Reich E, Lussi A, Newbrun E. Caries-risk assessment. Int. Dent. J. 1999 Feb;49(1):15-26.

[6]. Socransky SS. Dental biofilms: difficult therapeutic targets. Periodontol 2000. 2002;28:12-55.

[7]. Marsh PD. Dental plaque as a microbial biofilm. Caries Res. 2004;38(3):20411.

[8]. Gurenlian JR. The role of dental plaque biofilm in oral health. Am Dent Hyg Assoc . 2007 Dec 31;81(suppl 1):116.

[9]. Anup N, Vishnani P. Cariogram-a multi-factorial risk assessment software for risk prediction of dental caries. Int J Sci Stud. 2014;1(4):58-62.

[10]. Prabakar J, John J, Arumugham IM, Kumar RP, Srisakthi D. Comparative Evaluation of Retention, Cariostatic Effect and Discoloration of Conventional and Hydrophilic Sealants - A Single Blinded Randomized Split Mouth Clinical Trial. Contemp Clin Dent. 2018 Sep;9(Suppl 2):S233-S239.Pubmed PMID: 30294150.

[11]. Mathew MG, Samuel SR, Soni AJ, Roopa KB. Evaluation of adhesion of Streptococcus mutans, plaque accumulation on zirconia and stainless steel crowns, and surrounding gingival inflammation in primary molars: randomized controlled trial. Clin Oral Investig. 2020 Sep;24(9):3275-3280.Pubmed PMID: 31955271.

[12]. Khatri SG, Madan KA, Srinivasan SR, Acharya S. Retention of moisturetolerant fluoride-releasing sealant and amorphous calcium phosphate-containing sealant in 6-9-year-old children: A randomized controlled trial. J Indian Soc Pedod Prev Dent. 2019 Jan-Mar;37(1):92-98.Pubmed PMID: 30804314.

[13]. Prabakar J, John J, Arumugham IM, Kumar RP, Sakthi DS. Comparing the Effectiveness of Probiotic, Green Tea, and Chlorhexidine- and Fluoride-containing Dentifrices on Oral Microbial Flora: A Double-blind, Randomized Clinical Trial. Contemp Clin Dent. 2018 Oct-Dec;9(4):560-569.Pubmed PMID: 31772463.

[14]. Prabakar J, John J, Arumugham IM, Kumar RP, Sakthi DS. Comparative Evaluation of the Viscosity and Length of Resin Tags of Conventional and Hydrophilic Pit and Fissure Sealants on Permanent Molars: An In vitro Study. Contemp Clin Dent. 2018 Jul-Sep;9(3):388-394.Pubmed PMID: 30166832.

[15]. Mohapatra S, Kumar RP, Arumugham IM, Sakthi D, Jayashri P. Assessment of Microhardness of Enamel Carious Like Lesions After Treatment with Nova Min, Bio Min and Remin Pro Containing Toothpastes: An in Vitro Study. Indian J Public Health Res Dev. 2019;10(10):375-80.

[16]. Pratha AA, Prabakar J. Comparing the effect of Carbonated and energy drinks on salivary pH-In Vivo Randomized Controlled Trial. Res J Pharm Technol. 2019;12(10):4699-702.

[17]. Prabakar J, John J, Srisakthi D. Prevalence of dental caries and treatment needs among school going children of Chandigarh. Indian J Dent Res. 2016 Sep-Oct;27(5):547-552.Pubmed PMID: 27966516.

[18]. Kumar RP, Vijayalakshmi B. Assessment of fluoride concentration in ground water in Madurai district, Tamil Nadu, India. Res J Pharm Technol. 2017;10(1):309-10.

[19]. INDIRAN MA. AWARENESS AND ATTITUDE TOWARDS MASS DISASTER AND ITS MANAGEMENT AMONG HOUSE SURGEONS IN A DENTAL COLLEGE AND HOSPITAL IN CHENNAI, INDIA. Disaster Management and Human Health Risk V: Reducing Risk, Improving Outcomes. 2017 Sep 7;173:121.

[20]. Kumar RP, Preethi R. Assessment of Water Quality and Pollution of Porur, Chembarambakkam and Puzhal Lake. Res J Pharm Technol. 2017;10(7):2157-9.

[21]. Samuel SR, Acharya S, Rao JC. School Interventions-based Prevention of Early-Childhood Caries among 3-5-year-old children from very low socioeconomic status: Two-year randomized trial. J Public Health Dent. 2020 Jan;80(1):51-60.Pubmed PMID: 31710096.

[22]. Pavithra RP, Jayashri P. Influence of Naturally Occurring Phytochemicals on Oral Health. Res J Pharm Technol. 2019;12(8):3979-83.

[23]. Neralla M, Jayabalan J, George R, Rajan J, MP SK, Haque AE, et al. Role of nutrition in rehabilitation of patients following surgery for oral squamous cell carcinoma. Int. J. Res. Pharm. Sci. 2019 Oct 16;10(4):3197-203.

[24]. Leelavathi L. Nicotine Replacement Therapy for Smoking Cessation-An Overview. Indian J Public Health Res Dev. 2019 Nov 1;10(11):3588.

[25]. Sreenivasan PK, Prasad KVV, Javali SB. Oral health practices and prevalence of dental plaque and gingivitis among Indian adults. Clin Exp Dent Res. 2016 Jan 28;2(1):6-17.Pubmed PMID: 29744145.

[26]. Al-Haddad KA, Ibrahim YT, Al-Haddad AM, Al-Hebshi NN. Assessment of Gingival Health Status among 5- and 12-Year-Old Children in Yemen: A Cross-Sectional Study. ISRN Dent. 2013 Jun 26;2013:1-7.Pubmed PMID: 23878742.

[27]. Ekstrand KR, Bruun G, Bruun M. Plaque and gingival status as indicators for caries progression on approximal surfaces. Caries Res. 1998;32(1):41-5. Pubmed PMID: 9438570. 
[28]. Morinushi T, Lopatin DE, Tanaka H. The relationship between dental caries in the primary dentition and anti S. mutans serum antibodies in children with Down's syndrome. J Clin Pediatr Dent. 1995 Summer;19(4):279-84. Pubmed PMID: 7547486.

[29]. Garg A, Madan M, Dua P, Saini S, Mangla R, Singhal P, et al. Validating the Usage of Cariogram in 5- and 12-year-old School-going Children in Paonta Sahib, Himachal Pradesh, India: A 12-month Prospective Study. Int J Clin Pediatr Dent. 2018 Mar-Apr;11(2):110-115.Pubmed PMID: 29991863.

[30]. Celik EU, Gokay N, Ates M. Efficiency of caries risk assessment in young adults using Cariogram. Eur J Dent. 2012 Jul;6(3):270-9.Pubmed PMID: 22904655.

[31]. Hebbal M, Ankola AV, Metgud SC. Dental caries, salivary parameters and plaque scores as caries risk predictors among 12 year old school children-A follow up study. Int J Collab Res Intern Med Public Health. 2012;4(5).

[32]. Basha S, Swamy HS. Dental caries experience, tooth surface distribution and associated factors in 6- and 13-year-old school children from Davangere, India. J Clin Exp Dent. 2012 Oct 1;4(4):e210-6.Pubmed PMID: 24558557.

[33]. Lingström P, van Ruyven FO, van Houte J, Kent R. The pH of dental plaque in its relation to early enamel caries and dental plaque flora in humans. J Dent Res. 2000 Feb;79(2):770-7.Pubmed PMID: 10728979.

[34]. Sudhir KM, Kanupuru KK, Nusrath F, Embeti S, Chaitra NT. Validation of Cariogram as a tool for caries risk prediction among 12-year-old institutionalized children-a longitudinal follow-up study. J Oral Health Dent Manag. 2017;16:1-8.

[35]. Kidd EA. Caries management. Dent Clin North Am. 1999 Oct;43(4):74364.

[36]. Walsh LJ. Dental plaque fermentation and its role in caries risk assessment. International Dentistry South Afria (Australasian Edition). 2006;1(3):4-13. 